\title{
Rapid Geophysical Surveyor
}

EGG-M-92598

\author{
L.G. Roybal, G.S. Carpenter, N.E. Josten \\ Idaho National Engineering Laboratory \\ EG\&G Idaho, Inc.
}

P.O. Box 1625

Idaho Falls, ID $83415-3416$

\begin{abstract}
The Rapid Geophysical Surveyor (RGS) is a system designed to rapidly and economically collect closely-spaced geophysical data used for characterization of Department of Energy (DOE) waste sites. Geophysical surveys of waste sites are an important first step in the remediation and closure of these sites; especially older sites where historical records are inaccurate and survey benchmarks have changed due to refinements in coordinate controls and datum changes. Closely-spaced data are required to adequately differentiate pits, trenches, and soil vault rows whose edges may be only a few feet from each other. A prototype vehicle designed to collect magnetic field data was built at the Idaho National Engineering Laboratory (INEL) during the summer of 1992. The RGS was one of several projects funded by the Buried Waste Integrated Demonstration (BWID) program. This vehicle was demonstrated at the Subsurface Disposal Area (SDA) within the Radioactive Waste Management Complex (RWMC) on the INEL in September of 1992. Magnetic data were collected over two areas in the SDA, with a total survey area of about 1.7 acres. Data were collected at a nominal density of $2^{1 / 2}$ inches along survey lines spaced 1 foot apart. Over 350,000 data points were collected over a 6 day period corresponding to about 185 man-days using conventional ground survey techniques. This report documents the design and demonstration of the RGS concept including the presentation of magnetic data collected at the SDA. The surveys were able to show pit and trench boundaries and determine details of their spatial orientation never before achieved.
\end{abstract}

\section{INTRODUCTION}

Geophysics is playing an ever increasing and important role in the characterization and assessment of Federal waste and Superfund sites prior to remediation. However, the criteria for geophysical survey design and execution are quite different than those used for the more traditional uses of geophysics in the mining and petroleum industries. These criteria are primarily associated with the size and scale of the survey, and the scale of the objects to be detected. A high resolution conventional geophysical survey generally employs a sample spacing of a few meters by a few meters. This is not sufficient when trying to characterize a buried object that has a major dimension of a few feet. Additionally, the cost of performing a conventional geophysical survey with hand-held instruments becomes prohibitive as the size of the survey grid is reduced to accomodate small object resolution. Therefore, an automated approach for collecting geophysical data is required. The RGS presents a simple but efficient approach for collecting very closely-spaced geophysical data.

a. Work supported by the U.S. Department of Energy, Office of Technology Development, Under DOE Idaho Field Office Contract DE-AC07-76ID01570.

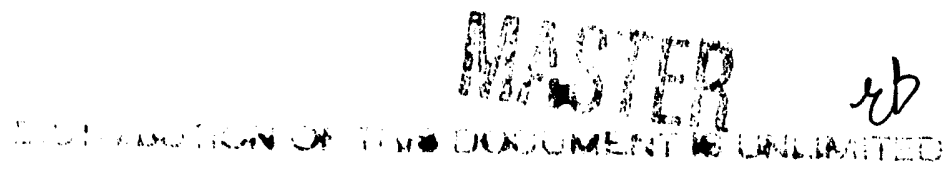


The RGS was field tested at the Subsurface Disposal Area (SDA) of the Radioactive Waste Management Complex (RWMC) on the Idaho National Engineering Laboratory (INEL). The RWMC is located in the southwestern corner of the INEL approximately 2 miles south of U.S. Highway 20 as shown in Figure 1. Two areas were surveyed with the RGS. The first area surveyed is located on the southcentral portion of the SDA. This area is part of a larger area previously surveyed by EBASCO Environmental in the spring of 1992 using hand-held ground equipment. A larger area corresponding to the location of Pits 9 and 7 was also surveyed. The locations of these areas within the SDA are shown in Figure 2.

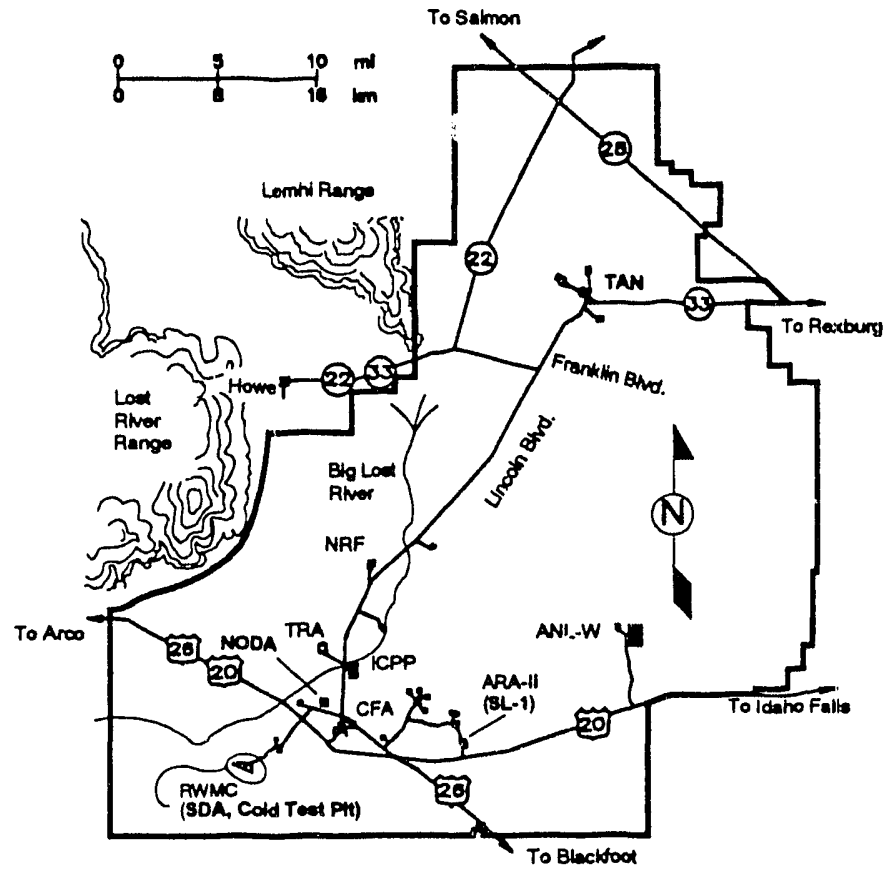

Figure 1. Loration of the RWMC Within the INEL.

The RGS was developed under the Buried Waste Integrated Demonstration (BWID) program. The BWID is chartered to jointly develop emerging technologies with the Department of Energy (DOE) and the private sector and apply these technologies to buried waste remediation efforts throughout the DOE.

\section{THE RGS SYSTEM DESCRIPTION}

The RGS was conceived by personnel in the Applied Geosciences Unit of EG\&G Idaho, Inc. as a simple device to collect precision magnetic data on DOE waste sites. The RGS was constructed in a very economical fashion primarily from off-the-shelf components. The initial RGS system was designed, field tested, revised and field demonstrated over the course of four months by INEL engineers and scientists. The major subsystems of the RGS include the sensors, the positioning system, the data logger, and the structure of the vehicle. The RGS design is modular such that a variety of sensors can be accommodated with minimal software and hardware modifications. A short description of these subsystems is provided in the following subsection. 


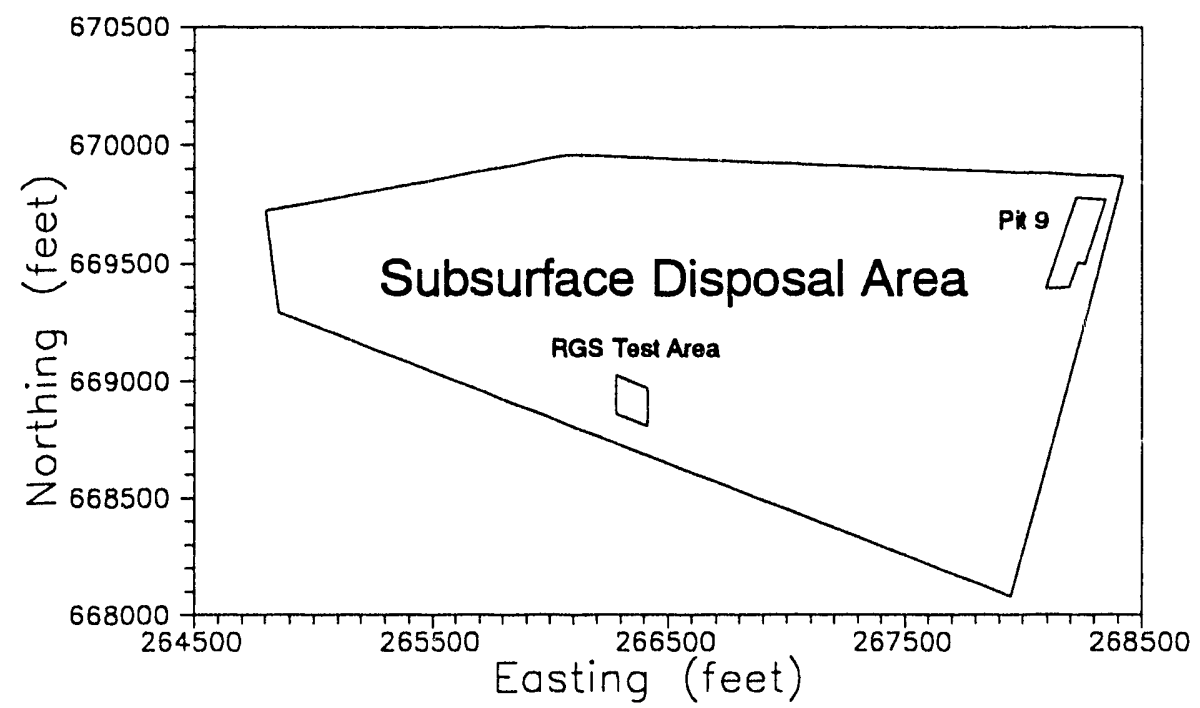

Figure 2. Survey Area Locations Within the SDA.

\section{RGS Major Subsystems}

The RGS sensors are comprised of four fluxgate magnetometers configured in gradiometer mode such that data along two survey lines can be collected simultaneously. They are mounted on the front portion of the vehicle as shown in Figure 3. The mounting system is designed such that the sensors can be moved horizontally and vertically to achieve a variety of configurations with respect to survey line width and sensor height. The current RGS sensors are vector instruments that measure the component of the Earth's magnetic field aligned with the axis of the magnetometer. The sensors are mounted vertically. Therefore, the measurement provided by the RGS sensors is the vertical gradient of the vertical component of the magnetic field. It is important to note that the RGS design is flexible in that almost any type or brand of sensor can be accommodated provided that the sensor meet the operating requirements of the RGS. The most important of these requirements is that the sensors be capable of operating at up to 50 $\mathrm{Hz}$ sample rates.

Positional control is accomplished by a calibrated measuring wheel system incorporated into the RGS. A radial encoder is attached to the measuring wheel's axle and sends electronic pulses to an onboard computer as the wheel rotates. Ground distance from a predetermined starting point is measured by counting pulses received by the on-board computer and multiplying the pulses by the wheel calibration factor. The measuring wheel is $61^{n}$ in circumference and the radial encoder outputs 128 pulses per revolution giving the measuring system a relative accuracy of about $0.48 \mathrm{in}$. along a survey line. This assumes that there is no slippage between the ground and the wheel and that the site is flat. Several field tests were performed on the measuring system that indicated the absolute accuracy of the system was about $2 \mathrm{in.}$ in $400 \mathrm{ft}$ over rough grassy terrain similar to that encountered at the SDA. Field tests on an asphalt parking lot indicated that the measurement was within 0.5 in. over a $300-f t$ span. Since the RGS is only capable of measuring straight line distance, the site of interest must be pre-surveyed using conventional ground survey techniques to establish a logical sequence of survey lines and define a relative coordinate system. This coordinate system can then be tied into local monuments or other survey control systems. 


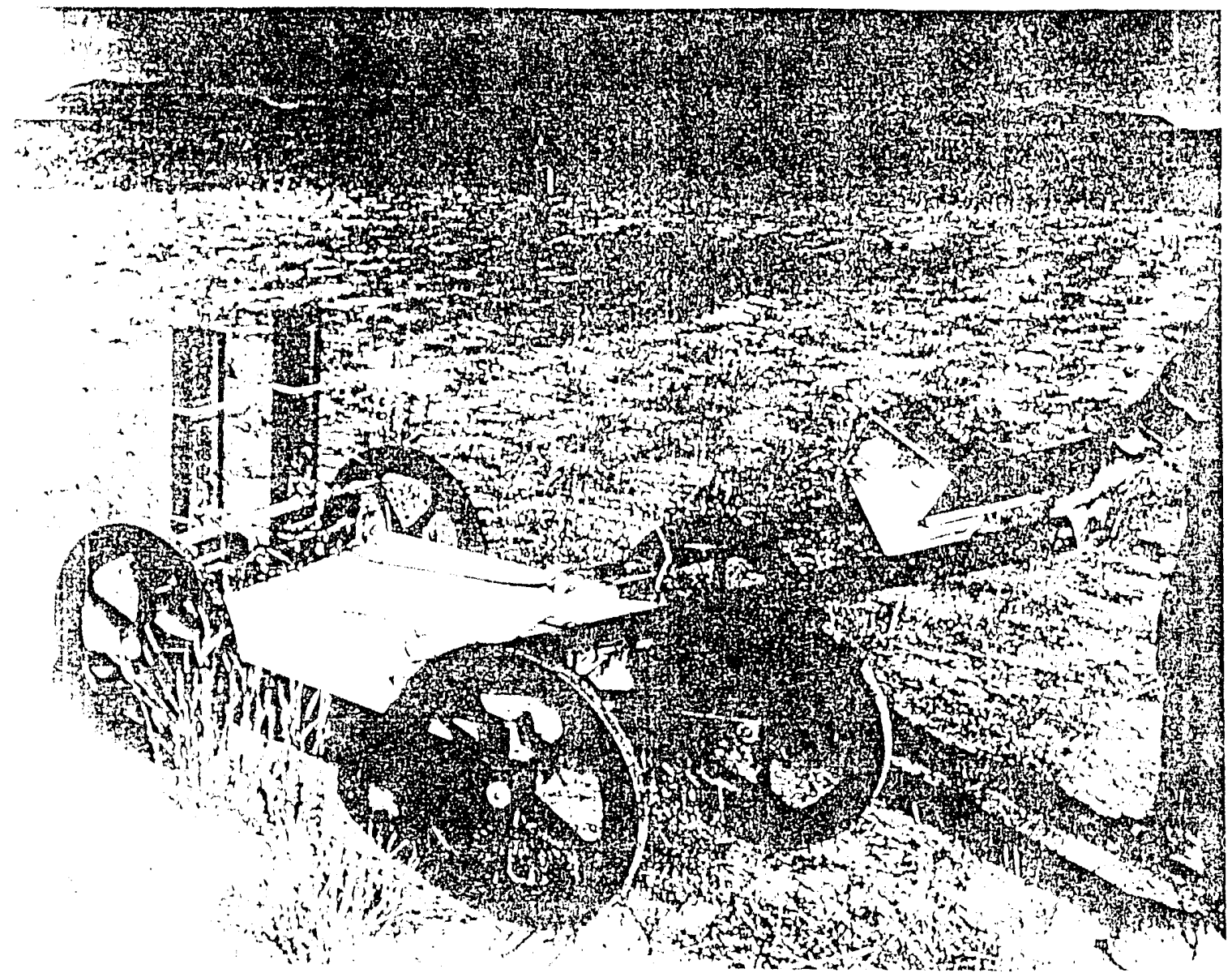

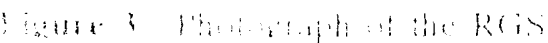

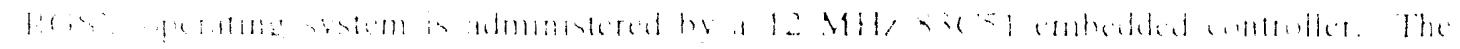

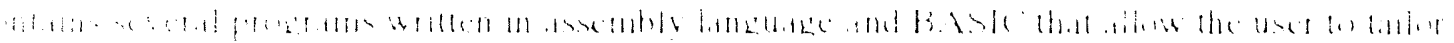

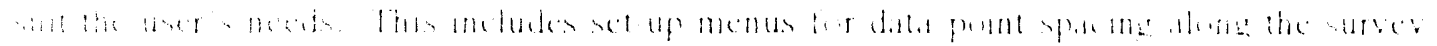

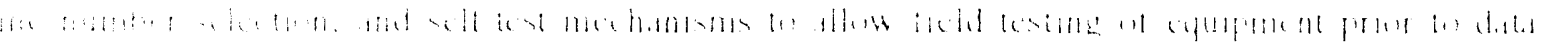

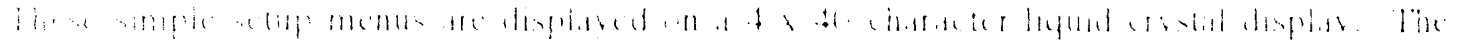

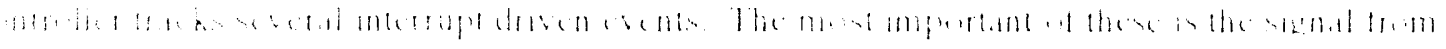

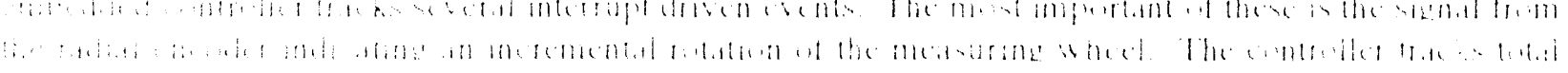

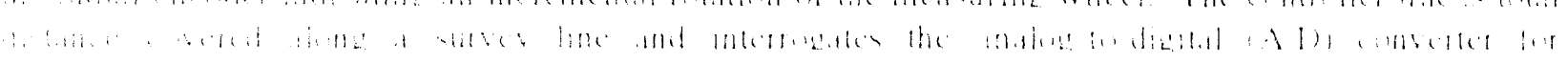

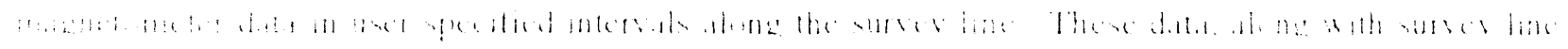

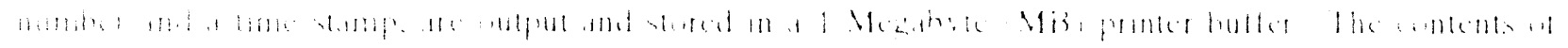

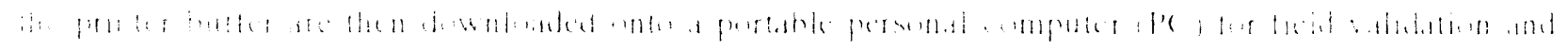

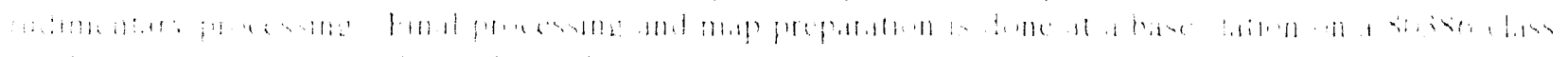

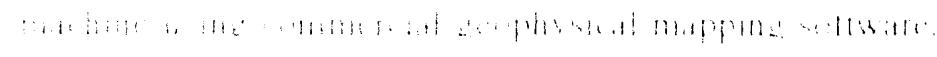

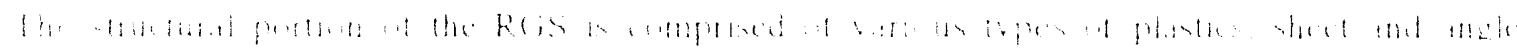

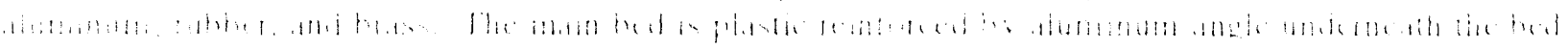

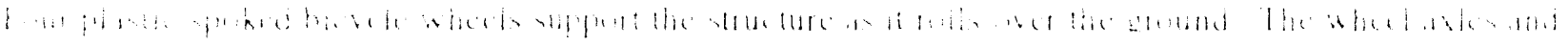

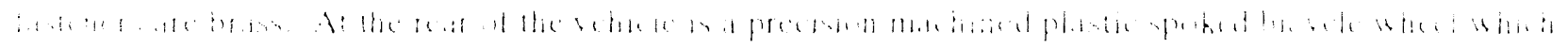

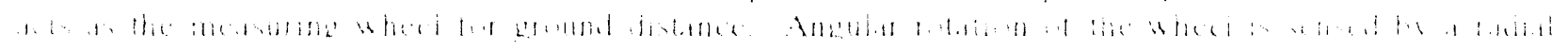

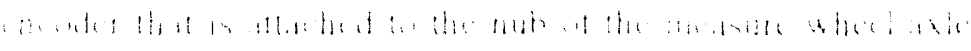




\section{RGS FIELD TESTING AND EVALUATION}

Two areas within the SDA were surveyed with the RGS. The first area surveyed is located in the southcentral portion of the SDA. The survey was accomplished over two days during the early part of September 1992. The RGS Test Area was initially to be the only area surveyed with the RGS. The objectives of the Test Area were to demonstrate the functionality of the RGS and show the value of collecting a high density data set for non-intrusive evaluation of DOE waste sites. The second area surveyed is located near the upper northeastern corner of the SDA and covered Pits 9 and 7. This survey was conducted over the last two weeks in September of 1992.

The Pit 9 survey was requested by the Environmental Restoration Department (ERD) of EG\&G Idaho, Inc. to clarify the boundaries and locations of the pits. This was an unplanned survey that had more of a production flavor to it rather then a demonstration project. However, the Pits 9 and 7 survey presented special operating difficulties to the RGS where the performance of the RGS under these conditions was an unknown. Therefore, some very useful operational data were obtained by performing this survey in addition to providing the information requested by the ERD. The relative position of these areas with respect to the SDA is shown in Figure 2.

\section{The RGS Test Area}

Figure 4 provides a description of the initial RGS Test Area investigated with the RGS. This area was selected for an initial demonstration of the RGS system for several reasons. First, this area presented ideal conditions for the RGS from an operational standpoint. The terrain was flat with very sparse vegetation. In this respect, interpretation issues rather could be highlighted without interference from operational issues of the RGS. Second, the RGS Test Area was the site of a previous "high-resolution" magnetic survey conducted by EBASCO Environmental ${ }^{1}$ during the spring of 1992 . This allowed for a direct comparison of the data collected by the RGS with existing magnetic data.

The RGS Test Area corresponds to a parallelogram approximately 164-ft deep x 145-ft wide. Historical records indicate that there are four trenches crossing this area shown as trenches $12,14,16,19$ in Figure 4. These trenches are oriented such that the centerlines are approximately $20-\mathrm{ft}$ apart. The trenches were estimated to be between 10 and 15 -ft wide, leaving 5 to $10-\mathrm{ft}$ of waste-free space between the trenches. Thie RGS survey area is shown as the solid outline parallelogram and the EBASCO survey in shown as the dashed outline area. The surveys do not directly coincide but co overlap within the area of interest.

The RGS Test Area survey was laid out and conducted according to established procedures for the RGS. Briefly, the Test Area was mapped, staked, and tied to an existing survey of the SDA such that direct correspondence with the EBASCO survey was maintained. Then, measuring tapes were stretched along the northern and southern boundaries of the area, and a third tape was moved in 1-ft increments between the two stationary tapes to act as a visual aid in navigating the RGS aloing a straight line. Data were collected on survey lines that were $1-\mathrm{ft}$ apart with measurements collected approximately every $21 / 2$ in. along each line.

The data were downloaded from the data logger onto a portable personal computer about every two hours during active data collection. This was done to limit the liability of collecting corrupt data and losing data during the download process. The data were quickly quality checked in the field on the PC by plotting a profile of one of the survey lines and visually inspecting for magnetometer response to waste 


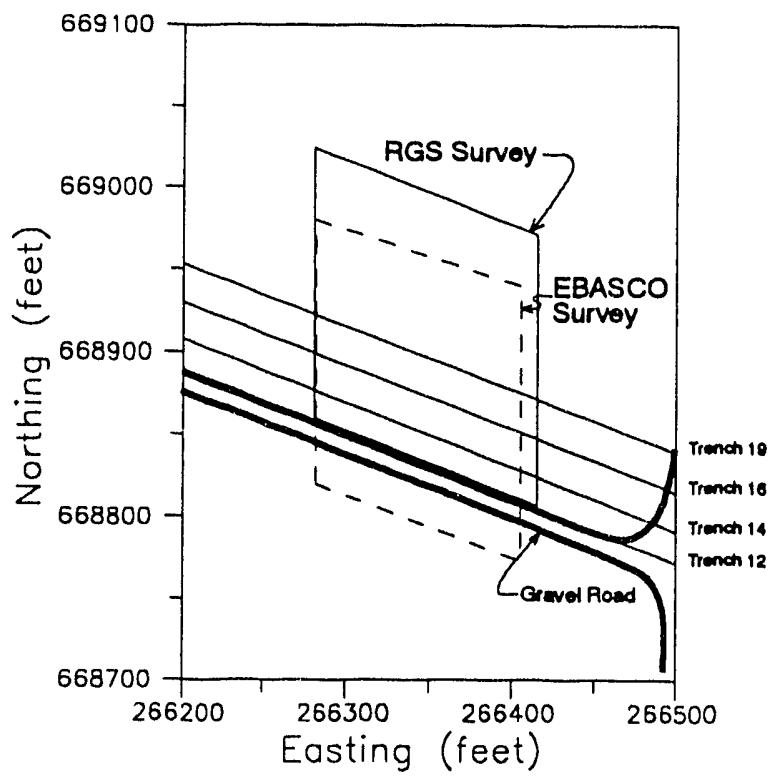

Figure 4. RGS Test Area Survey Location on the SDA.

and background anomalies. This was done with a combination of commercial and custom software developed to prepare the data for mapping and presentation. At this point, any errors associated with the measuring wheel repeatability and reliability were averaged over a survey line. This was done by computing a unique calibration constant for each line by knowing the number of pulses counted by the radial encoder on the measuring wheel and the true distance between the start and end points of the survey line. It was felt that this methodology for computing position along a line was more accurate than assigning a single constant for converting encoder pulses to distance.

\section{Test Area Results and Comparison with Existing Data}

The RGS was a success from a functional and operational standpoint. Functionally, the data logger and measuring wheel subsystems performed very well. Data were collected and downloaded without loss and the measuring wheel subsystem displayed excellent repeatability with an average deviation of only a few pulses out of an average of 4120 . The maximum deviation did not exceed 10 pulses which corresponds to a maximum error of about $5 \mathrm{in}$. in $140 \mathrm{ft}$. Since these errors were averaged over the entire line, the maximum positional error encountered was much smaller although difficult to quantify.

Figure 5 provides a comparison of color contour plots of the vertical gradient magnetic data collected with the RGS and an existing survey done by EBASCO Environmental over the RGS Test Area. The RGS data was collected on a 1 - $\mathrm{ft} \times 1$ - $\mathrm{ft}$ grid. The sensors displayed a $\pm 25 \mathrm{nT} / \mathrm{m}$ noise component similar to that encountered in the initial field tests. It is difficult to see this noise in the Figure because of the wide range in magnetic vertical gradient values over the RGS Test Area. However, the noise component is most evident in areas where the gradient is near zero. Also, closer inspection of the individual magnetic profiles reveals the noise component in the data. This noise is strictly a result of the sensors used for the initial demonstration and should be minimized as other sensors are installed onto the RGS. 
EBASCO Environmental conducted an extensive geophysical survey of the SDA that included The RGS Test Area during the spring of 1992. The purpose of the survey was to further delineate trench boundaries so that boreholes could be sited in the waste-free zones between the trenches. The EBASCO survey was conventional in the sense that measurements were made using standard hand-held magnetometers. Here, the station spacing between data points was one meter ( 3.28 feet) along survey lines and 4 meters (13.1 feet) between survey lines. The survey lines were oriented in the north-south direction. By current standards, the EBASCO grid would be considered a high resolution survey. However, the RGS data set corresponds to a 40x increase in data density compared to the EBASCO survey. Two observations concerning Figure 5 serve to illustrate the critical advantage provided by the RGS survey. The first concerns the appearance of "noisen in the data sets. The second concerns differentiating between anomalies caused by metallic waste and those caused by basalt. Both observations point to differences in data fidelity.

The RGS data contain a number of small circular anomalies (less than a few feet across), many of which occur as high-low dipole pairs. Some of the lower amplitude features reflect pure instrument noise. Many others mark locations of basaltic boulders scattered about on the ground surface. Still others may indicate locations of small metallic objects such as survey pin flags that have become buried through years of surveying and grading at the SDA. The key point concerning these anomalies is that they are easy to identify as "noise" based on their small size, the occurrence of the characteristic dipole pairs, and their somewhat random distribution. These subtle diagnostic features are recognizable only because the magnetic field has been so densely sampled by the RGS.

In contrast, the EBASCO data appear very smooth and noise free. These data were collected on a much coarser grid and many noise anomalies due to boulders or metallic debris were simply missed. Nonetheless, closer inspection reveals the presence of a number of noise features in the EBASCO data. These features are larger than their counterparts in the RGS data and typically do not exhibit a dipole character. They tend to line up along north-south lines corresponding to the individual data collection profiles, and tend to be slightly elongated in the east-west direction perpendicular to the profiles. In short, the shape, size and distribution of noise anomalies in the EBASCO data depends more on the distribution of data points than on the actual location and physical make-up of the noise sources. These features are simply undersampled or aliased. During the grid interpolation and contouring processes they become smoothly merged with anomalies caused by buried waste or basalt bedrock. Since the goal for interpretation is to differentiate anomalies from different sources, this is clearly an undesirable effect.

Undersampling and aliasing are also a concern for anomalies caused by larger magnetic sources since the interpreter relies on fairly subtle details of anomaly patterns in order to distinguish between buried waste and basalt. Buried metal, by virtue of its shallower depth and finite size, tends to produce very sharp, symmetrical anomalies. Compact metallic objects often have a well developed dipole character with a strong negative lobe located north of the positive lobe. By contrast, basalt tends to create smooth, serpentine anomaly patterns. Basalt anomalies build to full amplitude over broader areas and can be traced over longer distances. Dipole character is sometimes evident for basalt, but the negative lobes tend to be weaker and usually display the same serpentine patterns as for the positive lobes.

In the EBASCO data, the distinction between waste, basalt and noise is often obscure. Anomalies that appear isolated in the RGS data are blended together in the EBASCO data. These create compound anomalies that look much like basalt. Several of the noise anomalies in the EBASCO data could easily be confused for small waste objects. Because of undersampling, these features appear larger and more symmetric than they actually are. In cases where the EBASCO data contain anomalies that have clear 

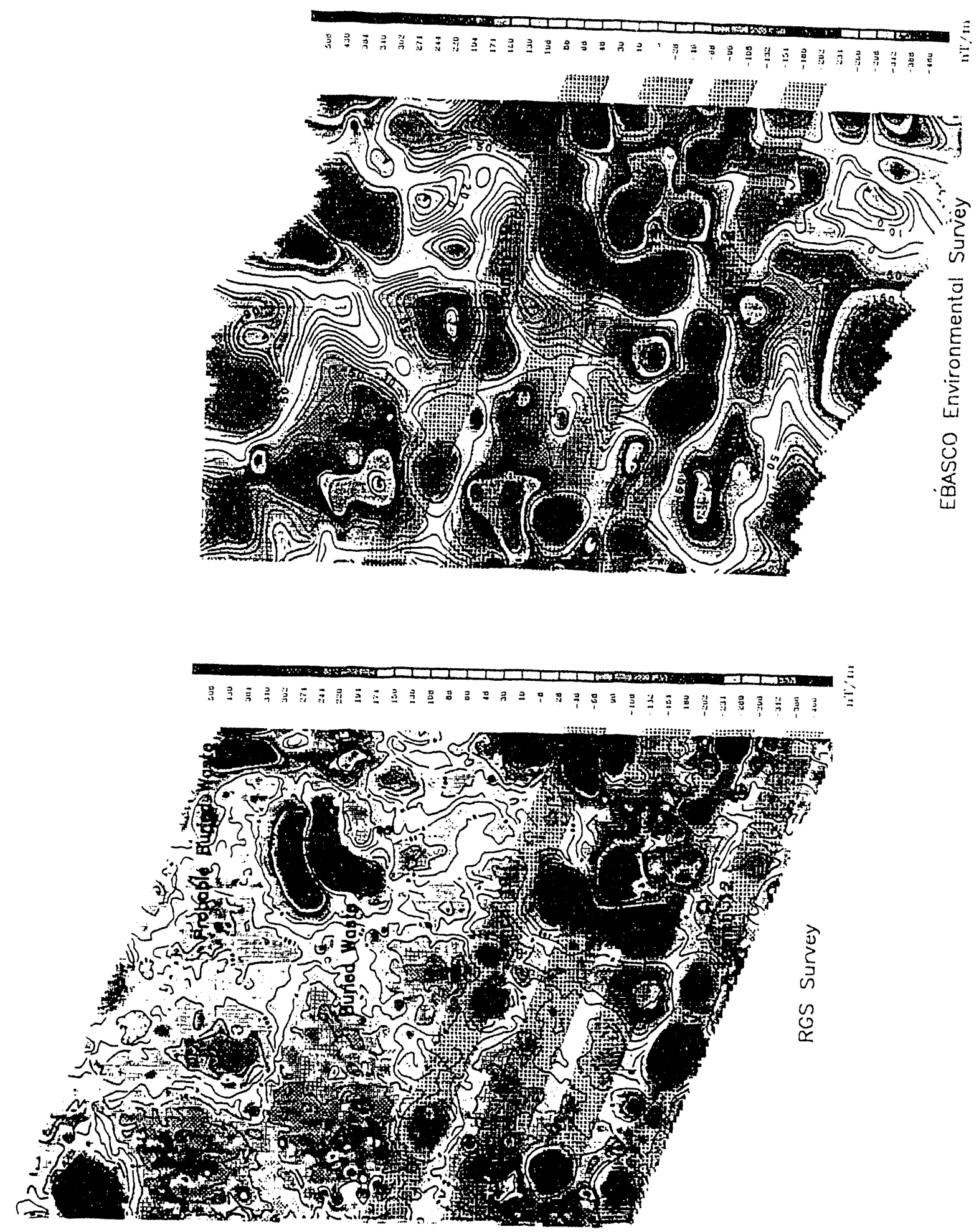

Figure 5. Comparison of RGS and Conventional Magnetic Vertical Gradient Data Sets. 
counterparts in the RGS data, the peak position is often shifted slightly. This occurs because the EBASCO data are not sampled finely enough to locate the true peak, which may be very sharp. These anomaly shifts change the way a trench boundary would be interpreted.

With few exceptions, buried metal anomalies are easily distinguished from basalt and noise anomalies in the RGS data. Sharp, symmetric features stand out clearly from background and are confined almost exclusively to the belts identifying the interpreted trench boundaries. In several cases, the accuracy of the trench boundary interpretation could be further improved by incorporating the finer anomaly resolution produced by the RGS data. In addition, it is possible to confidently identify the presence of buried metal to the north of the trench rows in an area that was historically assumed waste-free.

The preceding discussion of the RGS Test Area data sets is not intended as criticism of the EBASCO survey. The EBASCO survey was well thought out, properly executed, and accomplished within a tight budget. For most portions of the SDA, the EBASCO data provided a clear basis for interpreting trench boundaries consistent with the objectives for locating boreholes. However, for difficult problems like the RGS Test Area, conventional data sets begin to break down. Fundamental problems associated with undersampling become prevalent and the survey objectives cannot be met.

There is simply no substitute for collecting proper data. If the desired information is not contained in the data or is distorted by the data, it cannot be recovered even by sophisticated analysis. In defining the type of data that is "proper" for a particular survey, it is necessary to consider not only the targets of interest, but also all sources of potential noise. The survey must be designed to fully characterize the noise as well as the targets if there is any potential to confuse the two. The RGS simply provides a capability for collecting proper data at an acceptable cost.

\section{Pit 9 Survey}

A magnetic survey using the RGS was performed over Pits 9 and 7 within the SDA in response to a request by the EG\&G Idaho Environmental Restoration Department to determine the exact boundaries of the two pits. Figure 6 shows the approximate bounds of the magnetic survey of Pits 9 and 7 and is shown as the dashed area. The magnetic survey was extended 35-ft north of the documented Pit 9 northern boundary such that Pit 7 was included. The magnetic survey extended 10-ft west of the Pit 9 western boundary and 19-ft east of the documented eastern boundary. The magnetic survey was extended only to the edge of the southern Pit 9 boundary primarily because the main road into the SDA forms the southern edge. It was later discovered that the documented southern boundary of Pit 9 extends onto the main SDA road although the results of the magnetic survey do not support this statement.

The RGS Pit 9 survey was conducted in an attempt to settle concerns that the historical boundaries of the pit were inaccurate and that buried waste extended well beyond the accepted eastern boundary. These concerns were raised based on preliminary results from an electromagnetic survey that was conducted at Pit 9 as part of a DOE research project. It was understood that the targets for magnetic methods only partially overlap with those for electrical methods and that some types of waste would not be detectable with the RGS. However, results from the RGS Test Area survey convinced the INEL Environmental Restoration Program that they could at least settle the question as to whether common metallic waste (barrels or steel structural waste) extended outside the historical boundary.

Previous reconnaissance magnetic and electrical surveys conducted at Pit 9 showed that the pit contained large quantities of metallic waste throughout the pit area. ${ }^{2}$ In this sense the Pit 9 problem 


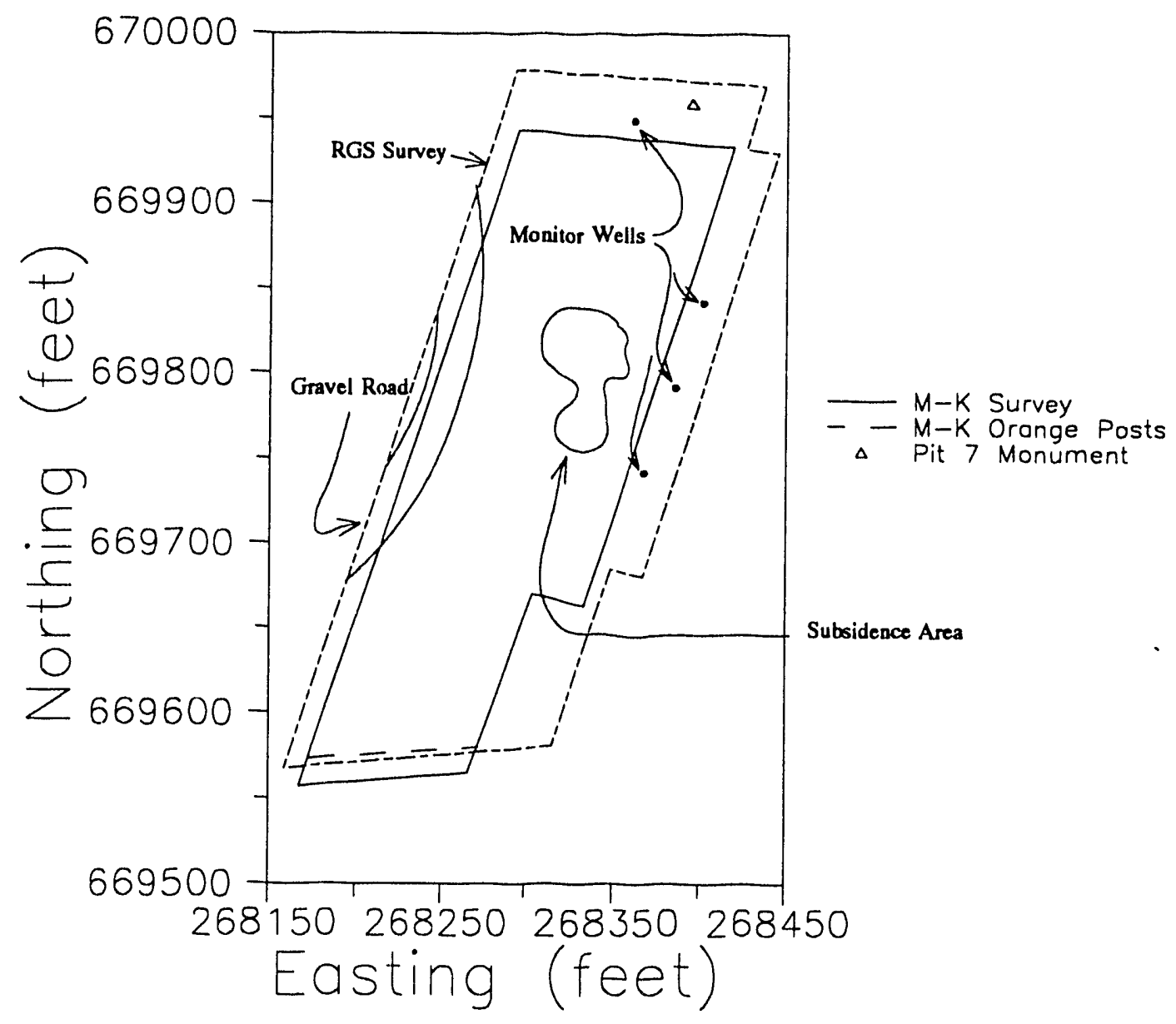

Figure 6. RGS Survey Bounds and Pit 9 Topography.

differed markedly from the RGS Test Area problem where metallic waste was sparse. Considering the widespread nature of metallic waste in Pit 9, a $2 \times 2-\mathrm{ft}$ or $3 \times 3-\mathrm{ft}$ grid would have been justified. Nonetheless, RGS data were collected on a $1 \times 1$-ft grid in part as a research venture, and in part because these data could be collected for a minimal cost in comparison with conventional data collection.

\section{Pit 9 Topography and Cultural Features}

The RGS survey of Pits 9 and 7 presented some special operational difficulties for the RGS because of surface irregularities and heavy vegetation over the Pit 7 area. Although the main surface of Pit 9 is generally flat, there are some large subsidences located on the central portion of the pit approximately $100-\mathrm{ft}$ south of the documented northern border. These subsidence features were caused by the collapse of wood and paper boxes containing buried waste through natural deterioration. There are three major subsidence areas located approximately around the 268350 Easting (E), 669800 Northing (N) coordinates. The largest of these areas is irregular in shape and about $30-\mathrm{ft}$ wide along its major dimension. These subsidence areas vary in depth from about 18 in. to 2 - $\mathrm{ft}$ below the flat portion of Pit 9. Also, the surface of the pit has been built up with fill dirt such that the northern and eastern borders are above the surrounding terrain. The northern border varies from about $1-\mathrm{ft}$ along the northwestern corner of the pit to 2 -ft at the northeastern comer of the pit above the exterior of the pit. The eastern 
border ranges from about 2 - $\mathrm{ft}$ at the northeastern corner to 3 -ft along the central eastern border above the exterior of the pit. Along the western border, a paved gravel road cuts a crescent across the central western border and has about a 1-ft high berm along the eastern edge of the road. These topographic features are important because the vector-based magnetometers used in this survey are particularly sensitive to tilt angle which can affect the data in these areas. The magnetic survey was truncated along the southern border of Pit 9 by the presence of the main road bed from the RWMC into the SDA. This road lies about 4-ft above the surface of Pit 9 . The Pit 9 area extends to the middle of this roadway according to the historical records. The magnetic survey extended to the flood control berm at the northwestern corner of the survey area. The northeastern corner of the survey area is approximately 8-ft from the flood control berm.

The area surveyed contained several monuments and monitor wells which are visible in the magnetic data and serve as excellent indicators of relative position. There are four monitor wells located outside of the pit boundaries: one along the northern boundary and three along the eastern boundary. The approximate locations of these wells are shown in Figure 6. There are several concrete monuments containing circular metal stamps located within the surveyed area. The Pit 7 monument is located north of Pit 9 and is shown in Figure 6. There are also concrete monuments indicating the outline of Pit 9. The locations of these monuments do not correspond with the historical records of the Pit 9 corners with the exception of the northeast and northwest corners. In these cases the historical records and the monuments are within 1-ft of each other. The outline of Pit 9 shown in Figures 6, 7, and 8 correspond to the historical survey records of Pit 9.

The survey of Pit 9 consisted of three main areas. The majority of the survey was done with the survey lines running in an east-west direction aligned with the northern border of the survey area shown in Figure 6. This represents a block of $140-\mathrm{ft}$ long (east-west) $x$ 395-ft wide. The small triangular area in the southern portion of Pit 9 was also surveyed east-west but the survey lines were of varying length due to the presence of the main SDA entrance road along the southern border of Pit 9 . This is important because the RGS measure wheel system was allowed to compute distance directly over this portion of the survey since there was no standard length to compare to (i.e. 140-ft wide) as in other portions of the survey. A 15 -ft wide by 300-ft long strip oriented along the easter border of Pit 9 was later added to the survey because it was apparent during post processing that initial survey edge was very close to the edge of the pit boundary. Much of this area is on approximately a 30 degree tilt and is rutted with rain washouts. Because of these conditions, the data from this strip are more qualitative than quantitative. The survey lines for this small strip were oriented roughly north-south in-line with the eastern border of the pit.

\section{Pit 9 Survey Results and Interpretations}

The Pit 9 area was surveyed with the RGS during a span of 4 days in September, 1992. The RGS was maneuvered over the Pit 9 survey area along survey lines spaced 2-ft from each other. Therefore, data were collected along survey lines spaced one-ft apart since the RGS has two gradiometers. -dta were collected along the lines approximately every $2 \frac{1}{2}$ in. although only data at one foot intervals were used to expedite the processing of the data. This corresponds to a data fidelity of about 256 times greater than that used in previous surveys of the Pit 9 area done by UNC Geotech ${ }^{2}$.

There were a number of problems encountered in the field while surveying the Pit 9 area. Most of these problems were likely related to the magnetometer sensors and their incompatibility with a field environment that incorporated hot and dusty conditions. In particular, when the magnetometers were 
saturated in a positive vertical gradient during warm afternoon outdoor conditions, they went off-line and could not be recovered until the power was removed and restored to the magnetometer. This behavior caused about a one and one-balf day delay in completing the survey which was originally scheduled to be completed on Sepiember 24 . Approximately 275,000 data points totaling about $10 \mathrm{MB}$ of data were collected by the RGS. Past experience indicates that this corresponds to about 185 man-days equivalent using conventional ground survey techniques. ${ }^{b}$

The positional control system displayed different calibration constants over different parts of the survey area. In particular, the northern area of the survey where surface vegetation was fairly heavy showed a longer (but consistent) calibration constant indicating some wheel slippage was occurring. The measuring wheel consistently counted about 25 pulses (out of 3500 ) less than the main surface of Pit 9. This was not unexpected since different surfaces (i.e. grass, asphalt, dirt) displayed different calibration constants during field testing. This did not present a serious problem because measuring wheel errors were averaged over each line by computing a unique calibration constant as presented earlier in the RGS Test Area discussion. More serious measuring errors were encountered along the eastern edge of the survey where large ruts and washouts were traversed during the course of the survey. Errors of up to two feet were computed along the eastern border which also had a large tilt angle due to the buildup of the Pit 9 surface. Although the measuring errors were averaged over this area, large positional errors of up to $1-\mathrm{ft}$ along the seven north-south survey lines collected in this area are possible.

The results from the RGS Pit 9 survey are presented in Figures 7 and 8 . The shaded relief presentation in Figure 8 provides a more intuitive, qualitative view of the data which serves to highlight the Pit 9 area against the background magnetic field. In this presentation, an imaginary light source is placed at a specified location above the three dimensional surface constructed from the vertical gradient data, and the reflection of light to an observer above the surface is computed and displayed. Here, the illuminated areas are the peaks of the surface and the dark areas are generally the valleys of the surface. The limits of buried metallic waste are clearly apparent on all sides of the pit. These apparent boundaries should be compared with the superimposed historical boundaries. The dynamic range of the vertical gradient magnetometers was limited to \pm 1640 nanoTesla/meter $(\mathrm{nT} / \mathrm{m})$. There are several instances in the data set where either maximum high or low values were achieved as evidenced by the flat regions in the extreme ranges of both the color contour and shaded relief plots of Pit 9 . The hashy appearance of portions of the shaded relief plot (Figure 8) is an indication of magnetometer noise related to some of the field failures and problems encountered during the survey. This is most apparent in Figure 8 along the eastern edge of the survey, the central portion of the survey, and the extreme southern portion of the survey.

The outline of Pit 9 is fairly evident to the eye from Figures 7 and 8 and requires little interpretation if gross boundaries accurate to within a few feet are satisfactory. This can be done by drawing a line through the inflection point in the color map as the gradient transitions between the magnetic lows and highs along the borders of the pit. A more exact interpretation of the boundary locations would require a detailed study of the individual magnetic profiles and is beyond the scope of this study as it is currently formulated. Also, the magnetic survey is a measure of the ferrous material buried in the pit and there is no guarantee that there are not some nonferrous wastes buried outside the bounds indicated by the magnetic survey. This would require an electromagnetic survey to reinforce the

b. Personal conversations with M.V. Carpenter, G.S. Carpenter, and N.E. Josten of EG\&G Idaho, Inc., September 1992. 


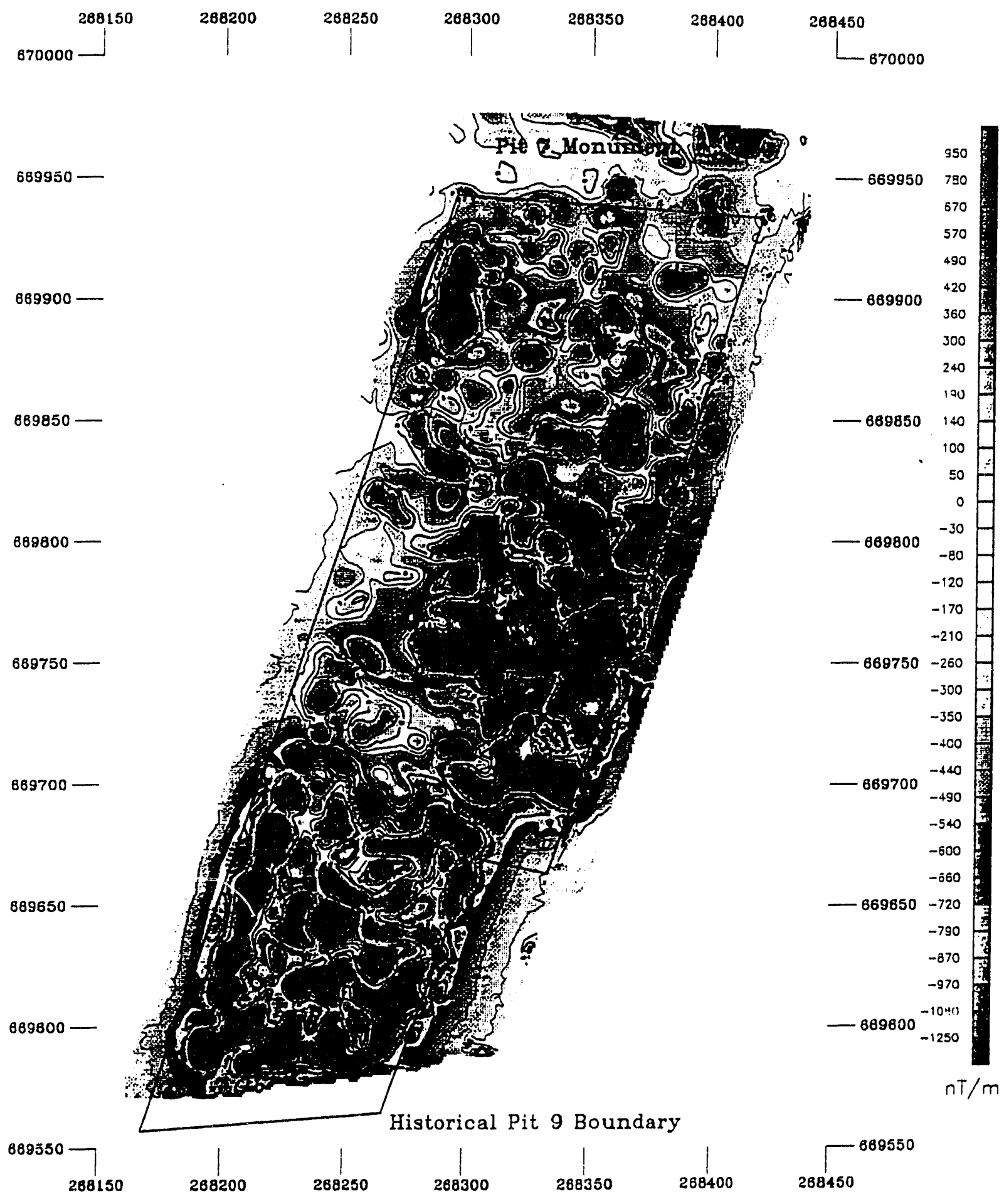

Figure 7. Pit 9 Survey, Magnetic Vertical Gradient. 


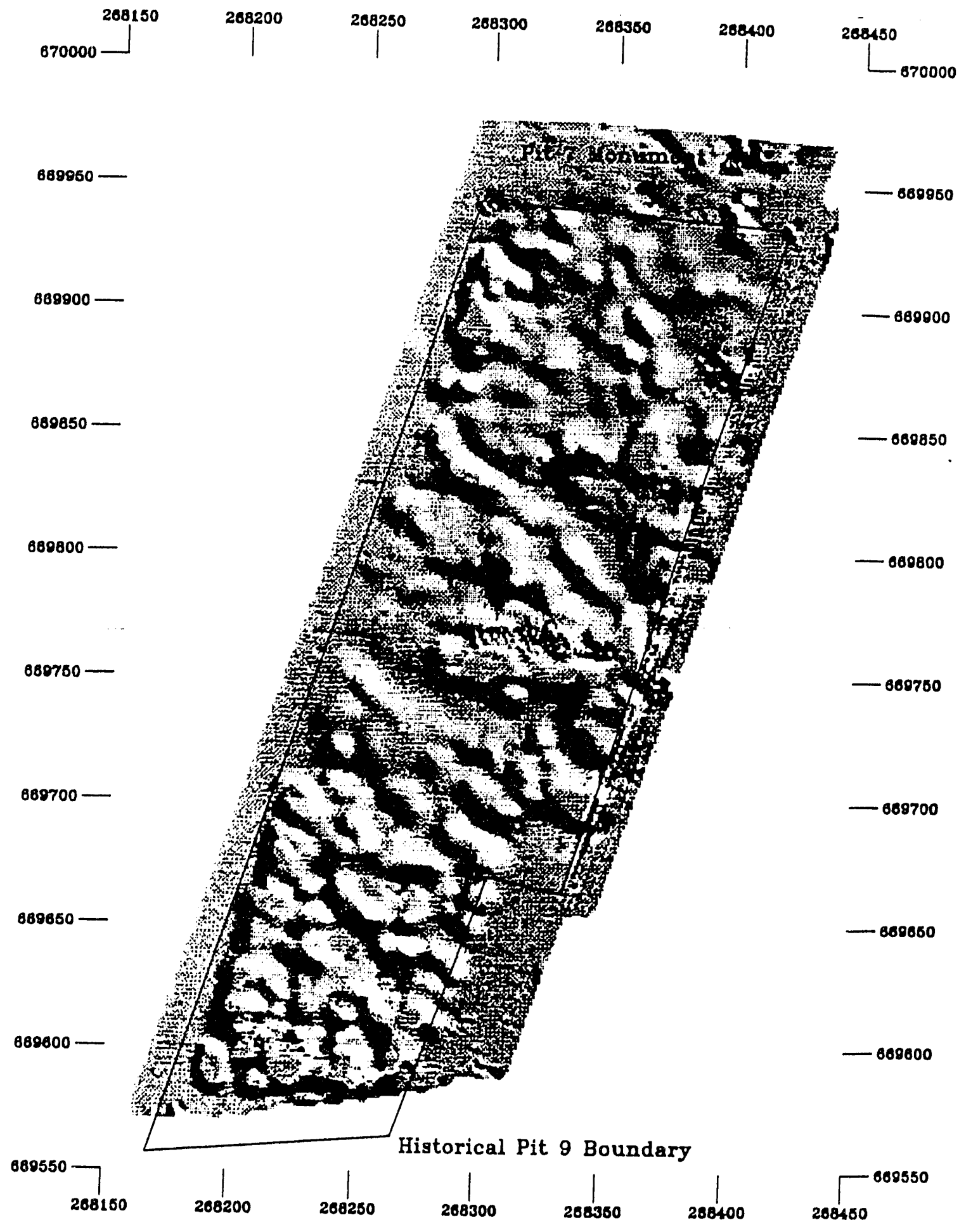

Figure 8. Pit 9 Survey, Shaded Relief of Magnetic Vertical Gradient. 
magnetic survey results. However, with these caveats in mind, the actual pit location compares fairly closely to the historical boundaries, especially along the western and eastern borders. The southern boundary does not extend nearly as far south as the historical records indicate, and the zig-zag in the eastern boundary is about 25 - $\mathrm{ft}$ north of the historical record. If fact, the southern boundary of Pit 9 is aligned remarkably well with the main road into the SDA from the RWMC and the older concrete monuments. Also, the appearance of the large anomaly extending beyond the northeastern border of Pit 9 indicates that an object or group of objects protrudes beyond the historical northern boundary along the northeaster corner of the pit. Discussions with RWMC and Pit 9 personnel indicated that a large piece of a reactor vessel may have been pushed into the pit wall during the initial disposal of waste at Pit $9 .^{\circ}$

Concrete monuments fitted with metal stamps mark several corners of Pit 9 and the center of Pit 7 to the north. Magnetic fields generated by the metal stamps created characteristic spikes that can be seen clearly in the RGS data. These monuments do not uniformly coincide with the documented historical corners of Pir 9 although they appear in several cases to yield a more accurate representation of the pit boundaries. The metal stamp anomalies provide a useful means to verify the positioning accuracy for the RGS data, since they tie the magnetic data directly to physical ground features. By placing small targets at key locations before conducting a survey, distortions caused by shortcomings of the mechanical measuring wheel could be neatly assessed. The low amplitude anomaly that cuts a crescent across the western Pit 9 boundary in Figure 8 was caused by tilting of the RGS as it crossed a low berm flanking a gravel road. Anomalies caused by steel casing in four sampling wells along the northern and eastern pit boundaries are clearly captured in the RGS data. The casing anomalies extend over a circular area about 15-ft in diameter surrounding the wells. The dense sampling interval makes it quite clear that these anomalies are separate from Pit 9 and there is no danger of misinterpreting them. If the survey had been performed at a coarser spacing, these anomalies may have merged with buried waste anomalies and raised questions regarding the northern and eastern pit boundaries.

Pit 7 is represented by the large magnetic high in the far northeastern corner of the survey. It is not clear that the smaller magnetic high centered at $669960 \mathrm{E}, 268375 \mathrm{~N}$ is or is not buried waste. This could likely be determined with additional analyses of the individual profiles comprising the magnetic survey, and an additional electromagnetic survey of the area. It is likely that part of Pit 7 is under the northern flood control berm for the SDA, but more data are required to ascertain the exact extent of Pit 7 to the north.

\section{RECOMMENDATIONS AND CONCLUSIONS}

The concept of the Rapid Geophysical Survey was successfully demonstrated. The prototype vehicle functioned as designed in outdoor field conditions by collecting spatially dense data sets in an extremely timely and economical fashion. In fact, collection of closely spaced data sets corresponding to that achieved by the RGS would never have been considered until now. More importantly, the RGS system demonstrated that high spatial density data sets are required if buried objects are to be located accurately. The economical collection of closely spaced data allows geophysicists to pursue quantitative analysis and modeling activities with high confidence that the phenomena modeled is compared to the true signature rather than a software synthesized signature. These types of requirements are being mandated by remediation activities in order to minimize the cost of handing unnecessary volume in the cleanup processes.

c. Personal discussions with R.B. Horton of EG\&G Idaho, Inc., September 1992. 
However, it is important to note that the RGS is still a prototype system. The authors recognize several shortcomings in the system as it is currently configured. The most serious of these is the use of the measuring wheel system to track distance along survey lines. The system employed performed better that expected, but a system designed to eliminate the need to survey along a systematic grid would increase productivity of the RGS. Several alternatives have been identified which require further investigation in the future. Improvements to the structure of the vehicle are necessary to dampen the shock load on the instruments and improve the stability of the cart over rough terrain. Also, it was apparent that more powerful computers are required to process large data sets. Processing the Pit 9 data set required an overnight operation on a $25 \mathrm{MHz} 80386 \mathrm{PC}$. Processing requirements will increase as even larger data sets are collected and analyzed with the RGS system.

The survey of the RGS Test Area located in the southcentral area of the SDA successfully demonstrated the usefulness of collecting spatially dense magnetic data. However, interpretation of trench boundaries over this particular area was difficult due to the sparseness of magnet:c materials in the trenches. This likely could be overcome by collecting more data with the RGS over a larger area such that the trench locations can be pieced together by extrapolating boundaries between areas demonstrating magnetic anomalies. Therefore, the RGS survey should be expanded to include areas on both sides of the current survey if accurate trench locations are desired in this portion of the SDA. There are many other areas in the SDA that would benefit from a high resolution magnetic survey of the SDA. This includes the upper northwest corner of the SDA where the historical trench locations were too close to together to resolve adequately from the EBASCO data. This is also true of the southwestern corner of the SDA where many of the soil vault rows, small pits, and trenches were unresolved in the EBASCO data set.

An automated magnetic survey tool like the RGS provides a great deal of useful data for waste site characterization. However, there is a need for a companion electromagnetic tool to augment the magnetic data sets collected with the RGS. The basic concept for an electromagnetic survey system is substantially similar to the RGS, with the major difference lying in the sensor package. The combination of closely spaced magnetic and electromagnetic data sets would provide a powerful characterization technology required to fully describe the DOE and non-DOE waste sites across the country.

\section{REFERENCES}

1. EBASCO Environmental Geophysics, "Subsurface Disposal Area Ground-Based Geophysics, EG\&G Engineering Design File ERD-WAG7-14, EG\&G Idaho, Inc., Summer 1992.

2. J.C. Hasbrouck, "Geophysical Surveys at INEL/RWMC Cold Pit, Acid Pit, and Pit 9", UNC Geotech, Grand Junction, Colorado, May 1989. 


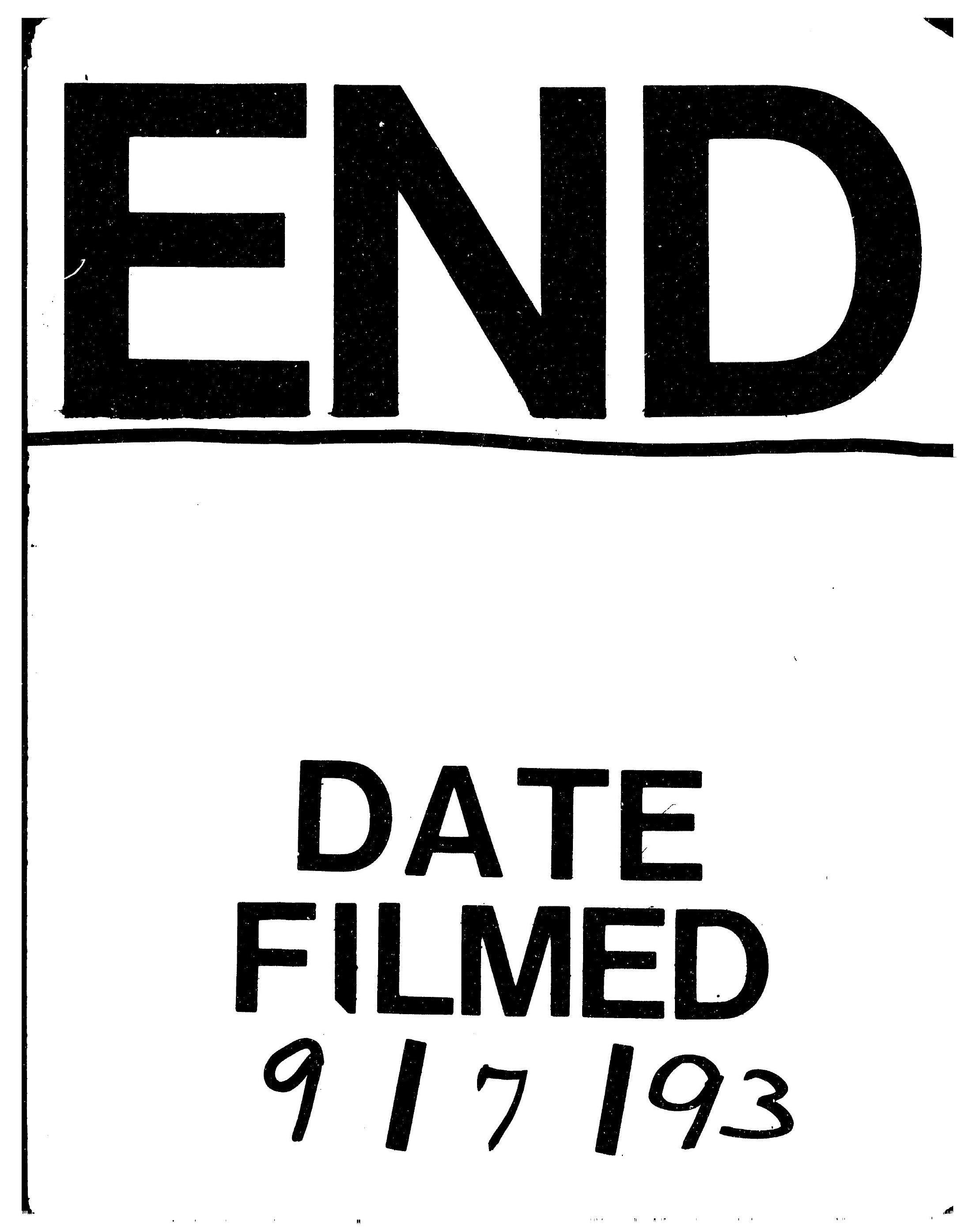


